\title{
Reubicación y expectativas de modernidad: el caso de las familias campesinas de Yanacona y el proyecto Aeropuerto Internacional de Chinchero (Cusco)
}

\author{
Marcos López Aguilar*
}

* Licenciado en Antropología por la PUCP. Actualmente cursa el segundo año de la maestría de Antropología Social y Etnología en la Escuela de Altos Estudios en Ciencias Sociales de París, Francia. Correo electrónico: marcos.lopez@pucp.pe

Fecha de recepción: 15/04/18. Fecha de aceptación: 14/01/19 


\title{
Reubicación y expectativas de modernidad: el caso de las familias campesinas de Yanacona y el proyecto Aeropuerto Internacional de Chinchero (Cusco)
}

\section{RESUMEN}

En diciembre de 2012, el Gobierno Regional del Cusco expropió los terrenos de la comunidad campesina de Yanacona para la ejecución del Aeropuerto Internacional Chinchero-Cusco. Además del pago de una compensación económica, se comprometió a encargarse del proceso de reubicación. El artículo analiza el proceso de «reubicación» de la población afectada y sus expectativas de modernidad. El análisis muestra que el Gobierno regional no realizó propiamente un proceso reubicación involuntaria: se limitó a indemnizar a las familias afectadas por sus viviendas. Sin embargo, la compensación económica no aseguró una reducción de los impactos negativos provocados por la reubicación. Esto fue posible, principalmente, por las expectativas de modernidad de la comunidad asociadas al proyecto.

Palabras clave: reasentamiento involuntario, tierras, comunidades campesinas, aeropuerto, Cusco.

\section{Resettlement and expectations of modernity: the case of peasant families of Yanacona and the Chinchero International Airport (Cusco)}

\begin{abstract}
In December 2012, the Regional Government of Cusco expropriated lands owned by the rural community of Yanacona in order to allow the construction of the International Airport at Chinchero (Cusco). In addition to the payment of economic compensation, it undertook to relocate the population affected by the expropriation process. The article focuses on analyzing the resettlement process of the affected population and their expectations of modernity. The analysis shows that Regional Government did not ensure the mitigation of negative impacts of an involuntary resettlement process. Indeed, it was limited to financial compensation for the houses that the affected families would lose. Consequently, Regional Government did not ensure the reduction of the negative impact generated by a relocation. This was possible mainly due to the community's expectations of modernity associated with the project.
\end{abstract}

Keywords: involuntary resettlement, land, peasant communities, airport, Cusco. 


\section{INTRODUCCIÓN}

A pesar de que han transcurrido casi cuarenta años desde que el Estado peruano comenzó a gastar dinero en el proyecto Aeropuerto Internacional Chinchero-Cusco (en adelante AICC) (Sumar, s.f.; Thorndike, 1983), la construcción todavía se encuentra en suspenso ${ }^{1}$. El primer documento oficial que hace mención al proyecto se encuentra en el Decreto Ley 23028, publicado el 7 de mayo de 1980 y firmado por el general Francisco Morales Bermúdez. En este se puede leer que el gobierno tomó la decisión de contratar a una empresa con el objetivo de realizar los estudios técnicos que permitan sustentar la construcción del aeropuerto en el distrito de Chinchero (provincia de Urubamba, región Cusco). Además, según consta en aquel documento, el proyecto era considerado, desde ese entonces, como necesario para fomentar el desarrollo del turismo en la zona sur del Perú como parte del Plan Copesco².

Hasta el inicio del segundo milenio, el proyecto no tuvo mayor relevancia en la política nacional. En el año 2001, el gobierno central promulgó la ley 27528, que disponía la actualización de los estudios técnicos realizados en la década de 1980 para iniciar el proceso de licitación. No obstante, el desacuerdo entre la comunidad campesina de Yanacona — propietaria de la mayor parte de terrenos necesarios para la construcción del aeropuerto- y la Copri ${ }^{3}$ —institución del Estado encargada de garantizar las condiciones para el inicio del proyecto — respecto de la compensación económica impidió que comience su construcción. De acuerdo con los miembros de la comunidad, el problema fue que la cantidad de dinero ofrecida por el Estado no correspondía a sus expectativas.

Nuevamente, el proyecto quedó en el olvido hasta el año 2010, cuando reapareció en la agenda política de la región Cusco. Según consta en el Acuerdo Regional 449-2010-GR, emitido el 22 de febrero del mismo año, el Gobierno regional tomó la decisión de asumir la construcción del aeropuerto con el objetivo de promover el incremento del turismo en el Cusco. A diferencia de lo ocurrido anteriormente, esta vez sí se inició un diálogo entre la comunidad de Yanacona y los representantes políticos de la región respecto de la compensación económica que deberían recibir los pobladores a cambio de sus terrenos.

\footnotetext{
1 El artículo fue escrito durante el ańo 2018, antes del inicio del movimiento de tierras para la construcción del aeropuerto.

2 El nombre completo al que hacen referencia las siglas es el siguiente: Comisión Especial para Supervisar y Supervigilar el Plan Turístico Perú - Unesco. Este proyecto — hasta la actualidad — tiene como objetivo la ejecución de proyectos de inversión que fomenten el desarrollo del turismo. El aeropuerto es uno de estos proyectos que podría aumentar el flujo de turistas en la región Cusco, lo que explica el interés de la población por que inicie su construcción.

3 Comisión de Promoción de la Inversión Privada que a partir de 2004 — junto a la Comisión Nacional de Inversiones y Tecnologías Extranjeras y la Gerencia de Promoción Económica de la Comisión de Promoción del Perú- formaría parte de la Agencia de Promoción de la Inversión Privada (Proinversión).
} 
En el año 2011, Jorge Acurio asumió la presidencia del Gobierno Regional del Cusco (2011-2013) y continuó el diálogo con la comunidad de Yanacona para conseguir que el proyecto se inicie durante su gestión. Es así que, en el año 2012, durante una asamblea general de la comunidad, Jorge Acurio se ofreció a pagar 20 dólares por cada metro cuadrado a cada uno de los comuneros afectados por el proyecto. Esta promesa fue el factor decisivo para la promulgación de la ley 29908, que convirtió al Gobierno regional en el sujeto activo de la expropiación de los terrenos necesarios para el inicio del aeropuerto. En diciembre de ese mismo año, el Gobierno regional concluyó la primera parte del proceso de expropiación de terrenos para el inicio del proyecto a través de la entrega de S/. 169235 536,90 millones a la comunidad de Yanacona (Gobierno Regional del Cusco, 2014). Este monto fue repartido al interior de la comunidad según el área que usufructuaba cada comunero, a razón de 20 dólares por metro cuadrado ${ }^{4}$.

Además de pagar por las tierras, según este documento, el Gobierno regional debía reubicar o reasentar a la población afectada por la expropiación. Es así como, el 18 de enero de 2013, se creó la Comisión Técnica Regional con el objetivo de implementar los procedimientos y acciones necesarias para la compensación y reubicación de las viviendas de las 101 familias de la comunidad de Yanacona afectadas por el proyecto ${ }^{5}$. En ese contexto, el presente artículo tiene como objetivo analizar el proceso de reubicación de las familias afectadas por el proyecto y comprender las razones que permitieron que este se lleve a cabo sin asegurar necesariamente una restauración o una mejora de las condiciones de vida de la población. Por eso, el artículo se divide en cuatro secciones. La primera consiste en un breve acápite metodológico que presenta las características generales del ámbito de estudio y explica la metodología utilizada. La segunda sección consiste en una discusión entre lo que el Banco Mundial (BM) y otras organizaciones multilaterales consideran como reubicación. Asimismo, se realiza un breve balance respecto de las investigaciones académicas realizadas sobre el tema y se presenta el concepto de expectativas de modernidad que consideramos importante para comprender las decisiones de la población de Chinchero con relación al proceso de reubicación. Finalmente, la tercera sección está dedicada al análisis del proceso de «reubicación» que se llevó a cabo en Chinchero para el inicio del proyecto del aeropuerto internacional.

\footnotetext{
4 Según el testimonio de los comuneros, los representantes del Gobierno regional y el documento del laudo arbitral que pude observar durante mi trabajo de campo, la tasa de cambio del dólar era de S/. 2.56.

5 Resolución Ejecutiva Regional 053-2013. Accesible en: http://regioncusco.gob.pe/transparencia/ attach/docs_normativo/resoluciones/2013/rer.2013.0069.pdf
} 


\section{Metodología}

El ámbito de estudio de la presente investigación es el distrito de Chinchero, ubicado en la provincia de Urubamba, a solo $30 \mathrm{~km}$ del circuito turístico más importante del Valle Sagrado de los Incas, donde se encuentra Machu Picchu. Esta ubicación estratégica es una de las razones que menciona constantemente el Gobierno Regional del Cusco para justificar la construcción del nuevo aeropuerto en este lugar. Asimismo, el distrito está conformado por trece comunidades campesinas, pero solo dos han debido vender terrenos para la construcción del nuevo aeropuerto internacional: la comunidad de Ayllopongo y la comunidad de Yanacona. Se podría decir que esta última es considerada como la más afectada, pues vendió 330 hectáreas de las 357 necesarias para el inicio del proyecto. Según el testimonio del presidente de la comunidad de Ayllopongo, fue la comunidad campesina de Yanacona quien dirigió las negociaciones con el Gobierno Regional del Cusco respecto de la expropiación de terrenos. Por esa razón, la presente investigación se realizó, principalmente, con comuneros y comuneras de los seis sectores de la comunidad de Yanacona: Nuevo Triunfo, Chaquellcocha, Querapata, Olones, Humanes y Huatata.

Esta investigación se basa en un trabajo de campo realizado durante los meses de agosto, septiembre y octubre del año 2015. Durante ese período, el investigador residió de manera permanente en el distrito de Chinchero y realizó entrevistas en profundidad con los comuneros y comuneras de los diferentes sectores de Yanacona a través de guías de entrevista semiestructuradas que tenían como objetivo comprender las razones que respaldaban la posición de la comunidad respecto del futuro aeropuerto internacional. En total, se realizaron treinta entrevistas con comuneros y autoridades comunales. También se realizaron entrevistas con funcionarios públicos vinculados con el proyecto del nuevo aeropuerto y pertenecientes a la comisión encargada de la reubicación de las familias afectadas. Además, se hicieron observaciones de las asambleas generales de comuneros. Este último es uno de los espacios comunales más importantes, pues no solo se toman decisiones, sino que también es el lugar donde los comuneros de los diferentes sectores de la comunidad exponen sus posiciones respecto de los proyectos que puedan afectar o beneficiar a la comunidad, como es el caso del aeropuerto. Finalmente, debido a lo delicado del proceso y la incertidumbre respecto de él, he decidido no mencionar los nombres verdaderos de las personas con el fin de preservar su anonimato.

\section{DESPLAZAMIENTO INVOLUNTARIO Y EXPECTATIVAS DE MODERNIDAD}

Uno de los impactos inevitables de los grandes proyectos de infraestructura es la transformación del espacio. Como señala Lefebvre (2013), la producción del espacio 
es resultado de una lucha de poderes entre dos o más actores, por ejemplo, entre el Estado y las comunidades campesinas. Como en toda disputa, la resolución - $\mathrm{O}$ victoria-implica la superposición de una perspectiva que determine, por ejemplo, el uso que tendrá el espacio. En el caso de los proyectos de infraestructura, la intervención de una zona implica, en la mayoría de situaciones, el desplazamiento de la población que la habita. Un costo que, según el discurso predominante en el Estado, debe pagarse por el desarrollo económico nacional y local. En otras palabras, se trata de obras de interés público cuya construcción beneficiaría a más personas de las que se podrían ver perjudicadas.

Existe una gran diversidad de proyectos de infraestructura para el desarrollo que implican el desplazamiento involuntario de la población: hidroeléctricas, carreteras, proyectos mineros, aeropuertos, etc. El inicio de la construcción de dichos proyectos transforma el espacio y, usualmente, genera un impacto negativo en las relaciones sociales de las personas que lo habitan a causa de la reubicación. Como señala Cernea (1988), las investigaciones han demostrado que el reasentamiento involuntario está asociado al incremento del estrés y de la mortalidad entre la población desplazada. Estas consecuencias negativas por lo general ocasionan una división entre la población local: por un lado, un grupo que se opone al inicio del proyecto a causa del impacto negativo que podría generar en el territorio y, por otro, un grupo que lo respalda, pues considera que las consecuencias serán positivas y, en menor medida, negativas.

Con el objetivo de reducir los impactos negativos causados por una reubicación, el Banco Mundial (BM) y el Banco Interamericano de Desarrollo (BID) han elaborado una política con lineamientos específicos que deben ser cumplidos en todos los proyectos que reciban su financiamiento. En este documento, ambas instituciones definen la reubicación involuntaria como un proceso completo de traslado y restablecimiento de los medios de subsistencia, condiciones de vida y sistemas sociales de una población de forma que este desplazamiento contribuya a su desarrollo (BID, 1999; BM, 2001). Según Cernea, esta política busca que, cuando la reubicación sea inevitable, se garantice que la población desplazada mejore o, por lo menos, recupere las condiciones de vida previas y sea integrada económica y socialmente en el nuevo espacio (1988b, p. 19). En otras palabras, se trata de establecer las condiciones mínimas para que los indicadores de bienestar material de las personas no se vean reducidos.

En caso que un proyecto tenga como consecuencia la privación de tierras utilizadas por la población, se plantean dos alternativas. Si la tierra es utilizada para la subsistencia, «deberá darse preferencia a las estrategias de reasentamiento que contemplen la entrega de tierras a las personas desplazadas» (BM, 2001, p. 4). En caso que la subsistencia no dependa de los terrenos requeridos por el proyecto, puede ser 
apropiado realizar una compensación económica en efectivo que «deberá ser suficiente para cubrir el costo total de reposición de las tierras y demás activos perdidos en los mercados locales» (BM, 2001, p. 5). En este último caso, no queda claro qué acciones debería tomar la institución responsable de la reubicación si, a pesar de que las familias no dependen de estas tierras para su subsistencia, viven allí.

Si bien la directiva del BM menciona la necesidad de incluir otros aspectos para no reducir la reubicación de la población a una compensación económica, los planes de reubicación involuntaria todavía parten de un enfoque teórico centrado únicamente en la compensación por pérdidas (Kanbur, 2003). Sin embargo, como señala Cernea (2003), la evidencia demuestra que los programas de compensación monetaria no impiden el empobrecimiento de las poblaciones desplazadas, pues los proyectos de infraestructura transforman la organización social. En consecuencia, la población reubicada pierde, por ejemplo, redes y vínculos con otras personas que no pueden ser compensados económicamente. Incluso puede ocurrir que su capital cultural no sea el adecuado para el nuevo uso que se dará al espacio y se vea excluida del desarrollo económico que provocaría el proyecto.

En el caso del sector minero, la mayor parte recibe financiamiento del BM, por lo que se encuentra en la obligación de elaborar planes de reasentamiento. No obstante, en el caso del proyecto Tintaya, este plan parece no haber sido suficiente. Según León (2015), este ha tenido impactos diferenciados en la población. Por un lado, la carga de trabajo en el caso de las mujeres es más pesada, porque deben administrar los bienes rurales con un menor apoyo de sus redes familiares. Por otro, parece haber un impacto positivo para los jóvenes, pues aprovechan mejor las oportunidades de empleo que genera la minería. En cambio, en los inicios del proyecto minero Las Bambas, la reubicación de la comunidad campesina de Fuerabamba generó conflictos al interior de las familias afectadas por el dinero recibido. Asimismo, la ubicación y la infraestructura de las viviendas construidas como parte del plan de reasentamiento son inadecuadas, porque se encuentran lejos de la capital donde se desarrollan las actividades económicas y la crianza de animales, por lo que actualmente nadie reside allí de manera permanente (Taj, 2017).

En el caso de los proyectos de infraestructura de transporte que se realizan en el Perú, el Ministerio de Transportes y Comunicaciones (MTC) ha elaborado un Marco conceptual de compensación y reasentamiento involuntario (2005) que establece las «Directrices para la elaboración y aplicación de planes de compensación y reasentamiento involuntario para proyectos de infraestructura» (2004). Estos documentos fueron realizados gracias a que el Programa de Caminos Departamentales recibía financiamiento del BM y el BID. Por esa razón, las directrices y el marco conceptual de compensación reasentamiento involuntario son coherentes respecto de las políticas elaboradas por el BM y el BID que mencioné anterior- 
mente (Ministerio de Transportes y Comunicaciones, 2005, p. 2). Según Castillo Cajas, el objetivo de las directrices elaboradas por el Ministerio de Transportes y Comunicaciones es regular «las opciones que tienen la autoridad competente y/o el privado ejecutor del proyecto para adquirir los derechos de propiedad que son necesarios para implementar la carretera» (2014, p. 181). No obstante, si bien estas directrices son consideradas como obligatorias en el caso de la infraestructura vial no queda claro si ocurre lo mismo en el caso de otros proyectos de transporte, como un aeropuerto.

En el caso de la ampliación del Aeropuerto Internacional Jorge Chávez, el Ministerio de Transportes y Comunicaciones debió reubicar el asentamiento humano El Ayllu, para lo cual elaboró un plan de reasentamiento involuntario. En ese caso, a través de la ley 29836 se realizó la expropiación de los terrenos adyacentes al aeropuerto y se estableció que el reasentamiento de la población afectada se realizara según las directrices elaboradas por el Ministerio de Transportes y Comunicaciones. Según De la Puente (2015) esto fue posible porque «la figura de los reasentamientos [por proyectos de inversión] está pautada desde el año 2001 gracias a la ley 27446, Ley del Sistema Nacional de Evaluación de Impacto Ambiental» (p. 39). Esto quiere decir que, como parte del estudio de impacto ambiental, se debía implementar un plan de reasentamiento o reubicación de la población afectada que debía ser aprobado por la Dirección General de Asuntos Socioambientales del Ministerio de Transportes y Comunicaciones. Este plan debía garantizar la reubicación de la población según la normativa nacional. En el caso de la ampliación del Aeropuerto Internacional Jorge Chávez, se elaboró un plan de reasentamiento y, en un principio, la población afectada se negó a abandonar los terrenos hasta que culminase la construcción de las viviendas donde debían reubicarse. A pesar de esta resistencia, terminaron por abandonar los terrenos requeridos para la ampliación del aeropuerto sin que el Ministerio de Transportes y Comunicaciones cumpliera con el plan de reasentamiento que se les propuso (De la Puente, 2013).

En el caso del nuevo aeropuerto internacional que se pretende construir en Chinchero, la situación es diferente. En primer lugar, el encargado de realizar el proceso de expropiación fue el Gobierno Regional del Cusco que, a diferencia del Ministerio de Transportes y Comunicaciones, no cuenta con un equipo con experiencia en la elaboración de planes de reasentamiento. En segundo lugar, la ley 29908, a través de la cual se realiza la expropiación de terrenos para el proyecto AICC, no hace ninguna referencia a las directrices elaboradas por el Ministerio de Transportes y Comunicaciones ni a un estudio de impacto ambiental que contemple un plan de reasentamiento involuntario. Por tal razón, en ningún momento el Gobierno regional elaboró un plan acorde las normativas internacionales que contribuyera a mejorar las condiciones de vida de la población afectada. En tercer lugar, a pesar de 
no existir un plan de reasentamiento, la población local del distrito de Chinchero no se opuso de manera directa a la construcción del nuevo aeropuerto.

Una de las razones para entender la ausencia de una oposición por la población local ante el proceso de reubicación son sus expectativas de modernidad. Según Ferguson (1999), las expectativas de modernidad de la población local en relación con una obra de infraestructura - la construcción de un nuevo aeropuerto, una carretera o un proyecto minero- hacen referencia a las ideas de cambio y desarrollo que esta genera en la población local. Este tipo de expectativas se encuentra en la narración de una historia lineal de desarrollo que la población local construye a partir del proyecto de inversión. Así, este aparece como una oportunidad a futuro que, por ejemplo, debería aumentar la cantidad de trabajo y mejorar las condiciones de vida.

Este tipo de expectativas no parece ser un elemento muy importante en los trabajos de investigación que se realizan respecto de los proyectos de inversión y las comunidades campesinas. La mayor parte de investigaciones se concentra en el impacto de la infraestructura una vez que esta ya ha sido construida o en la oportunidad que esta representa para el desarrollo económico de la población local (Borasino y Escobedo, 2010; Fort, 1999; Rozas y Sánchez, 2004; Zegarra, 2010). Aparentemente, no existen muchas investigaciones que intenten comprender la perspectiva de las personas con relación a los proyectos de infraestructura antes de su construcción. En el caso de Chinchero, donde la oposición de la población local respecto de una posible transformación del territorio parece ser mínima, las expectativas de modernidad representan una interesante pista de investigación para estudiar las razones que se encuentran detrás de la toma de decisiones de las personas frente a un proceso de reubicación.

\section{El Caso de la COMUNidAd de Yanacona: El PROCESO DE «REUbicación» DE LAS FAMILIAS AFECTADAS POR EL PROYECTO AEROPUERTO INTERNACIONAL}

\section{La ausencia de un plan de reasentamiento y las opciones de compensación económica}

La construcción del futuro aeropuerto internacional fue la causa por la cual 101 familias pertenecientes a la comunidad campesina de Yanacona que vivían al interior del denominado polígono del aeropuerto - espacio que comprende los terrenos requeridos para el inicio del proyecto- debieron ser reubicadas. En esa situación, una de las opciones era que se lleve a cabo un Plan de Compensación y Reasentamiento Involuntario (PACRI). Según el Ministerio de Transportes y Comunicaciones (2005), el objetivo de los PACRI es reducir los impactos negativos que afrontan las poblaciones desplazadas para que cuenten con las mismas o mejores condiciones de vida. 
En el caso del proyecto AICC, esto no fue lo que ocurrió. El 18 de enero de 2013 se creó la Comisión Técnica Regional ${ }^{6}$, encargada de implementar los procedimientos y las acciones para la compensación y reubicación de la población afectada por el futuro aeropuerto. Estos lineamientos fueron aprobados el 30 de abril de 2013, como consta en la directiva 006-2013-GR7. Tres cosas llaman poderosamente la atención respecto de este documento. Por un lado, se enfoca en la infraestructura afectada — las viviendas_, mas no en las familias. Por otro, el marco legal de la directiva no menciona ninguno de los documentos elaborados por el Ministerio de Transportes y Comunicaciones. Finalmente, la denominación con la que se refiere a las familias cambia de «afectadas» a «beneficiarias».

En la directiva se menciona como objetivo principal la «reubicación de viviendas a terrenos de propiedad de los beneficiarios [...] con la correspondiente habilitación urbana y [que] comprende la ejecución de obras de accesibilidad, distribución de agua, recolección de desagüe, distribución de energía eléctrica e iluminación pública» porque «las conexiones domiciliarias serán solicitadas y asumidas por los beneficiarios» (Gobierno Regional del Cusco, 2013, p. 6). En consecuencia, el Gobierno Regional del Cusco no se responsabiliza, por ejemplo, de garantizar la inserción laboral de la población ni de reducir otros posibles impactos asociados a la pérdida de actividades económicas que puedan ser resultado de la reubicación y que no forman parte de esta directiva. En otras palabras, no parece haber una preocupación por las condiciones de vida de la población, sino únicamente por su compensación económica.

¿Por qué el Gobierno regional no realizó un PACRI si se trataba de un desplazamiento involuntario? Existen dos versiones provenientes de los testimonios de los representantes del Gobierno regional. La primera versión es la del asesor legal de la Comisión Técnica Regional. Para él, no se realizó un PACRI por la siguiente razón:

Es que antes no podíamos hablar de este proyecto [AICC] si los terrenos no eran comprados, no eran del Estado. De nada serviría hablar de un proyecto si no tiene terreno propio. Entonces, la ley [29908] [...] nosotros [el gobierno regional], como manifiesto, estábamos desarrollando ya el PACRI [...] Pero cuando nosotros estábamos desarrollándolo, Proinversión nos manifestó que la ley no nos precisaba eso. Entonces hicimos un estudio sucinto y sistemático de la norma ${ }^{8}$, también con anuencia de Proinversión. Y, sí, arrojó que no había ningún

\footnotetext{
6 Resolución Ejecutiva Regional 053-2013. Accesible en http://regioncusco.gob.pe/transparencia/ attach/docs_normativo/resoluciones/2013/rer.2013.0069.pdf

7 Directiva 006-2013 que contiene los lineamientos para la liberación del área del Aeropuerto Internacional Chinchero - Cusco.

8 El asesor legal del proyecto se refiere a la ley 29908 que autorizó la expropiación de terrenos para el inicio del proceso de licitación del proyecto Aeropuerto Internacional Chinchero - Cusco.
} 
componente jurídico que le irrogue al gobierno regional desarrollar el PACRI. Por eso, nosotros hacemos la directiva [006-2013] únicamente. La directiva de un lineamiento, por llamarlo así, cuasi PACRI que nos diga qué es lo que debemos hacer, cuánto tenemos que pagar, cuáles son las alternativas. Los instrumentos que nosotros trabajamos para hacer estas directivas están basados en los PACRI que desarrolla el Ministerio de Transportes y Comunicaciones. Pero la ley no nos irroga hacer un PACRI (comunicación personal, 7 de septiembre de 2015).

Durante la entrevista, el asesor legal del proyecto AICC se refería a la ley 29908 para justificar que no se hubiese realizado un PACRI. Además, cómo él mismo señala, «no existía ningún componente jurídico que le irrogue al Gobierno regional a desarrollar el PACRI». En el caso de los proyectos privados de inversión minera, estos se encuentran regulados por organismos multilaterales como el BM o el BID y se ven en la obligación de proceder con un PACRI, como ocurrió en el caso de la población de Yanacancha por el proyecto Antamina (Salas, 2008). Al parecer, esta medida que obligue al Gobierno regional a realizar un plan de reasentamiento con estándares similares a los del BM estuvo ausente en el desplazamiento de la población a causa del proyecto del aeropuerto.

La segunda versión es la del ex jefe del proyecto AICC. Según su testimonio, el Gobierno regional no realizó un PACRI porque compró los terrenos a la población afectada:

En un primer momento, antes de que se empiece a definir en torno al terreno, el Ejecutivo nacional, a través de Proinversión, lo que quería era tomar los terrenos por necesidad y utilidad pública, es decir, no pagar. Entonces, cómo tú no pagabas, ¿no es cierto? Pero si había viviendas, en esa situación, tú podías aplicar el PACRI. ¿Por qué? Porque tenías que reasentar a la gente que vivía allí. En caso de nosotros, no ocurrió lo mismo. Nosotros compramos el terreno [...]. Entonces, como los compró, no había el tema del PACRI, pero sí había el tema de las viviendas y la reubicación (comunicación personal, 15 de septiembre de 2015).

Ninguna de las versiones explica de manera clara por qué no se llevó a cabo un PACRI. Por un lado, el asesor legal señala que la ley 29908 no se lo exigía. Por otro, el ex jefe del proyecto considera que este no se hizo porque el Gobierno regional compró el terreno. Sin embargo, legalmente no fue una compraventa sino una expropiación resuelta a través de un laudo arbitral. En todo caso, el testimonio de ambos funcionarios públicos muestra que no existe una normativa clara que obligue a las instituciones del Estado a realizar un PACRI en este tipo de proyectos.

En el Perú, las directrices del PACRI han sido establecidas por el Ministerio de Transportes y Comunicaciones y aprobadas a través de resolución 007-2004MTC/16. Sin embargo, al parecer estas no son de carácter obligatorio para todos los proyectos de infraestructura. Como señalé anteriormente, en el caso de la 
ampliación del aeropuerto Jorge Chávez, la reubicación del asentamiento humano El Ayllu implicó la elaboración de un PACRI acorde a lo establecido por el Ministerio de Transportes y Comunicaciones. En cambio, en el caso de Chinchero, la ley 29908 que permitió la expropiación de terrenos no hace referencia a ninguna normativa que establezca cómo se debió realizar la reubicación de la población afectada. Al parecer, el asesor legal del proyecto se refirió a este vacío legal cuando mencionó que no existía ninguna norma que irrogue al Gobierno regional implementar un plan de reasentamiento involuntario. Por lo tanto, en palabras del asesor legal del proyecto AICC, la comisión encargada de llevar a cabo el proceso de reubicación elabora un «cuasi PACRI» cuyo marco legal toma en cuenta los lineamentos elaborados por el Ministerio de Transportes y Comunicaciones, pero no parece contribuir al objetivo principal de los planes de reasentamiento: el restablecimiento o mejora de las condiciones de vida de la población desplazada.

A través de la directiva 006-2013, el Gobierno regional se comprometió a pagar por la infraestructura de las viviendas y colocar los servicios básicos (luz, agua y desagüe) en la zona donde las familias decidieran construir sus nuevas casas. Según el asesor legal del proyecto AICC, el Gobierno regional no podía encargarse de adquirir los nuevos terrenos donde se realizarían estas construcciones porque sería pagar dos veces por lo mismo:

Imagínate, en una primera instancia pagamos el terreno, ¿cómo volveríamos a pagar por un terreno más cuando ya lo hicimos? Entonces, solo quedaba pagar la infraestructura. Eso sería un delito, o sea, volver a pagar de lo mismo. Claro este caso [es] sui generis; si ellos no hubieran sido posesionarios y sí propietarios, tanto del terreno como de su infraestructura, hubiera sido el caso usual de edificarles y comprar otro terreno en otro lugar (comunicación personal, 7 de septiembre de 2015).

Según el testimonio del asesor legal del proyecto, la situación, luego de la expropiación de terrenos, era la siguiente: el Gobierno regional se convirtió en el dueño de los terrenos sobre los cuales se encontraba la infraestructura construida por las familias que vivían al interior del polígono de aeropuerto. Entonces, según los miembros de la Comisión Técnica Regional, se trataba de una reubicación de las viviendas, pero no necesariamente de la población. Por lo tanto, la Comisión Técnica Regional no inicia — stricto sensu - un proceso de reubicación de estas familias, sino que se limita a indemnizarlas por la pérdida de sus viviendas. La comisión se refiere a esta compensación como reubicación.

En esta situación, el Gobierno regional, a través de la directiva 006-2013, presenta tres alternativas a los titulares de las viviendas. La primera - la compensación económica directa - indicaba que, conforme a la valorización de las viviendas y bienes de posesión, el Gobierno regional contrataría una empresa constructora que 
edifique las viviendas en la zona elegida por los comuneros. La segunda opción la compensación económica asistida - consistía en dar a los comuneros el dinero equivalente a la valorización de su vivienda y bienes de posesión con el fin de que este sea administrado para la construcción de una vivienda que sería supervisada por profesionales proporcionados por el Gobierno regional. La tercera - la compensación económica de libre desarrollo- consistía en entregarles una compensación económica cuyo uso dependería completamente de las decisiones de los comuneros.

Estas tres opciones permitían a los titulares de las viviendas o bien utilizar el dinero de la compensación para una nueva casa supervisada por el Gobierno regional u obtener el dinero para utilizarlo con el fin que considerasen más adecuado. La tercera opción era la más atractiva para los representantes del Gobierno regional, porque encargarse de la construcción de nuevas casas alargaría el inicio del proyecto; en cambio, entregar el dinero a la población afectada les permitía concluir rápidamente con el proceso de reubicación, siempre y cuando cumplieran con la instalación de servicios básicos. Además, también era una opción interesante para aquellas personas que no pensaban utilizar el dinero en construir una vivienda y para quienes deseaban realizar una construcción sin los parámetros impuestos por el Gobierno regional. Esta libertad de decisión, según la comunicación personal que tuve con el asesor legal del proyecto AICC, fue la razón por la cual todos los titulares de las viviendas identificados por la Comisión Técnica Regional eligieron la tercera opción.

En las conversaciones que mantuve con los comuneros, pude darme cuenta de que hubo otras razones. Todos los comuneros y comuneras con quienes conversé me comentaron que no estaban de acuerdo con el modelo de vivienda ofrecido por el Gobierno regional. Según el testimonio de los pobladores afectados, la mayoría quería construir una casa de más de dos pisos o, por lo menos, con columnas que permitieran construir una infraestructura más alta en el futuro. Para que esto fuera posible, tenían que ser casas de ladrillo y cemento y no de adobe, como las que tenían sobre los terrenos expropiados. Según me comentó el ex jefe del proyecto AICC, el Gobierno regional ofreció hacer casas de adobe de un mismo modelo que no coincidían con las expectativas de las personas afectadas:

Mira, se ha estructurado un diseńo [...] siempre se ha dicho que no se debe romper con la estructura arquitectónica de la localidad. En ese sentido, se han diseñado unas viviendas [de adobe] de dos pisos [...] El comunero, como contaba con la plata, tenía su dinero en ese momento, no hizo caso y dijeron «yo contrato mi profesional». Pero la propuesta que se les ha alcanzado es en relación a dos pisos (comunicación personal, 15 de septiembre de 2015).

De acuerdo con este testimonio, los afectados prefirieron construir viviendas con cemento y no con adobe. Esto se debe a tres razones asociadas a las expectativas 
de modernidad de la población local. Primero, el cemento es usado por arquitectos e ingenieros para la construcción de edificios y obras públicas, por lo que es asociado no solo al progreso —entendido en términos de modernización y urbanización - sino que también es percibido como un material con un prestigio social superior al adobe (Harvey, 2010; Harvey y Knox, 2012). Socialmente, según el testimonio de los pobladores de Chinchero, las casas de cemento y ladrillo están asociadas al desarrollo y el progreso económico de las familias. Incluso el apelativo "noble», con el que usualmente se le califica, indica una asociación a un estatus social superior frente al adobe.

Segundo, si bien construir una vivienda de ladrillo y cemento es más costoso respecto a una casa de adobe, esta es más resistente y puede soportar más de dos pisos. En comparación con años anteriores, estas familias sí tenían el dinero suficiente — producto de la compensación que recibieron por la expropiación de sus terrenos - para construir una vivienda con cemento, ladrillo, e insertarle otros acabados, como cerámica al interior o en la fachada de la vivienda. Este dinero permitía materializar sus expectativas de modernidad al transformar una edificación rural en una propiamente urbana.

En el caso del proyecto AICC, las expectativas de modernidad de las familias afectadas se relacionan con los cambios que provocará el aeropuerto respecto del desarrollo económico de Chinchero. Para la mayoría de personas, construir una vivienda de material noble podría ser crucial para aprovechar los cambios que generaría la construcción del proyecto. Uno de los comuneros afectados me comentó lo siguiente acerca de las expectativas de sus compañeros y compañeras:

La mayoría de comuneros ha decidido [recibir el dinero] en efectivo y ya cada uno ve qué modelo [de vivienda] y cómo [la construye]. Porque la propuesta del gobierno regional era solamente al valor de lo que se ha calculado tu vivienda [...] La vivienda que [ellos] tenían seguramente su valorización alcanzaría para dos pisos. Entonces, ellos teniendo esa expectativa [una casa de más de dos pisos] y el gobierno regional no te va hacer con esa plata lo que tú te estás proyectando sino una vivienda con servicios y nada más (comunicación personal, 21 de septiembre de 2015).

Este testimonio relaciona las expectativas de modernidad de los comuneros con el desarrollo y la modernización que aparentemente generará el aeropuerto cuando inicie su construcción. La gran mayoría de comuneros y comuneras cree que, como parte del desarrollo económico que causará el proyecto, vendrán muchas más personas con el interés de vivir de manera temporal o permanente en el distrito.

Para la mayor parte de los pobladores, construir una vivienda de material noble y de varios pisos sería una opción para tener departamentos que pudieran alquilar a los futuros habitantes del distrito. Además, la inversión inmobiliaria es, en sí misma, 
una importante alternativa en una situación de incertidumbre, pues su valor tiende a incrementarse. Sin embargo, nadie puede asegurar realmente que el proyecto elevará el número de personas dispuestas a alquilar viviendas en Chinchero. Ante esa situación de incertidumbre, la inversión inmobiliaria es una estrategia para obtener un beneficio en el futuro y para aprovechar los cambios que podrían ocurrir en el distrito con el inicio de la construcción del aeropuerto.

\section{La compra de terrenos a la comunidad de Yanacona para la reubicación}

Como hemos señalado anteriormente, las 101 familias afectadas debían conseguir un nuevo lugar para reubicarse. Para 49 de ellas, esto no representaba un problema, pues contaban con viviendas en otras zonas del distrito. Sin embargo, para las 52 restantes, la situación era distinta, porque habían perdido una cantidad significativa de tierras utilizadas para la agricultura debido al proceso de expropiación. Además, no todas tenían viviendas donde mudarse y debían utilizar terrenos de uso agrícola para construir sus nuevas casas. Para evitar esto, el segundo grupo solicitó a la comunidad de Yanacona que les otorgase un lugar para poder reubicarse. Según el ex presidente del sector de la comunidad más afectada por el proceso de reubicación, la asamblea comunal accedió a otorgarles nuevas tierras:

Éramos 101 familias, de las cuales los que realmente vivíamos en ese polígono [interior de los terrenos expropiados para el proyecto aeropuerto] éramos 52 [...]. Las otras casas, como eran 101 [familias], sus dueños ya han fallecido. En algunos casos vivían sus hijos, pero la comunidad no ha permitido: «esa casa tú no te has construido, es de tu papá y ya ha fallecido. Te lo vas a cobrar. ¿Cuántos hijos son? Cinco hijos. Ya, de los cinco van a cobrar esta casa, pero lo van a repartir entre los cinco». Entonces, los 52 de los 101 [familias] en la asamblea nos han calificado. Ellos [los 52 comuneros que representaban a las 52 familias] sí se han construido. Entonces para ellos hay que darles un lugar de terreno (comunicación personal, 26 de agosto de 2015).

De esta forma, la Asamblea General de la comunidad aceptó venderles un lote de terreno de $250 \mathrm{~m}^{2}$ —al precio de 20 dólares por metro cuadrado — a cada una de las 52 familias de la comunidad en el lugar de Andenes. Según los testimonios de los comuneros y comuneras con quienes conversé, se trataba de terrenos que eran utilizados por la persona que debía pasar el cargo principal de mayordomo de uno de los santos patrones de la comunidad. En el siguiente mapa se puede observar la ubicación geográfica de los terrenos donde se reubicaron las familias afectadas por el proyecto AICC con el rótulo de Nueva Yanacona, como es conocido localmente. 
Mapa 1. Modificación del mapa político del distrito de Chinchero elaborado por el equipo del Plan de Desarrollo Urbano en 2015

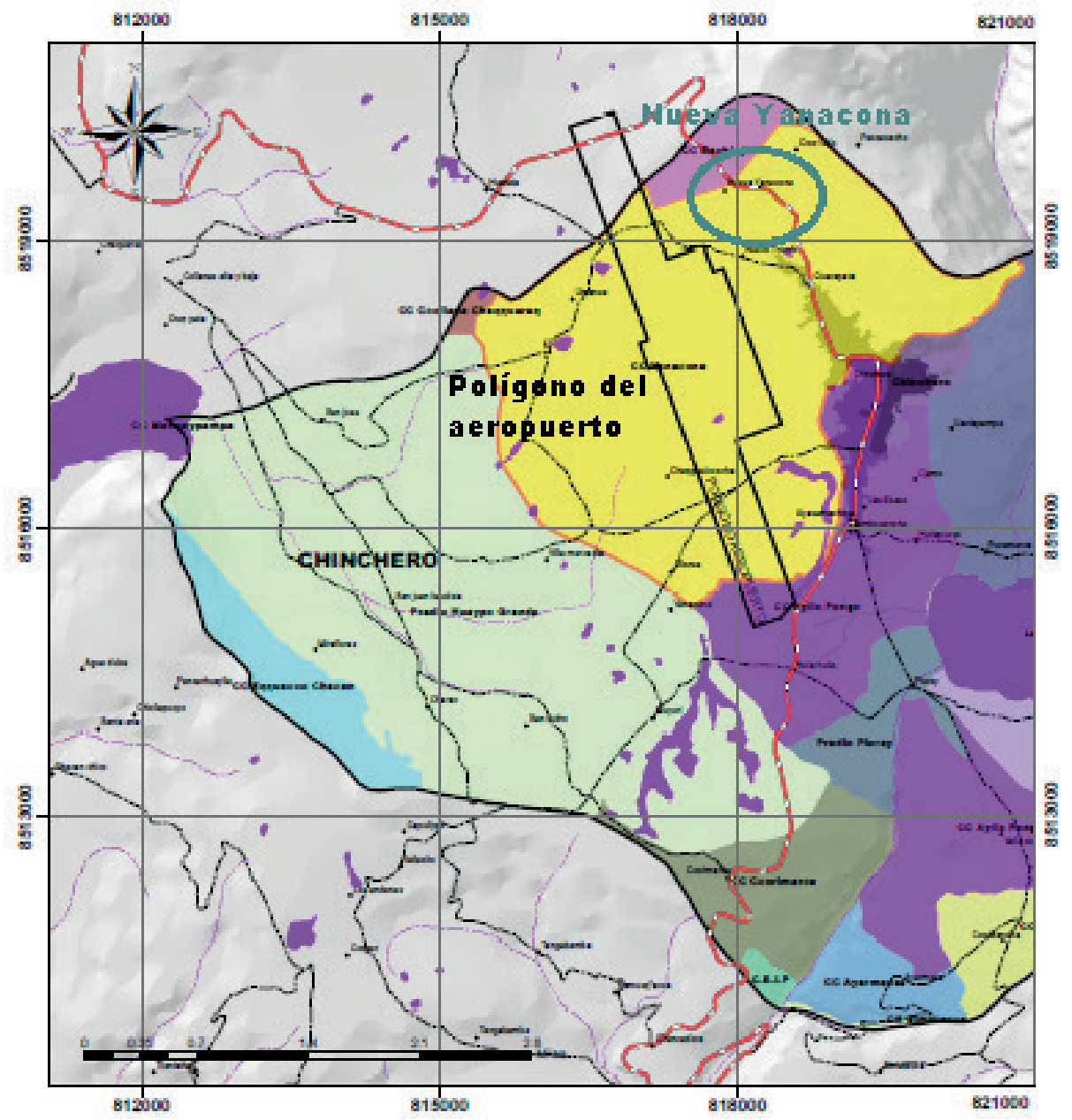

Fuente: Ministerio de Vivienda, Construcción y Saneamiento, 2015.

\section{El desplazamiento de los comuneros y la liberación del polígono del aeropuerto}

Este conjunto de terrenos no contaba con ningún tipo de conexión de luz, agua y desagüe y ni siquiera se encontraba habilitado para la edificación de viviendas. En ese momento, esto no parecía ser un problema, porque el Gobierno regional se había comprometido a instalar los servicios básicos en el lugar donde los comuneros y comuneras decidiesen construir sus nuevas viviendas y, además, apoyarlos con el saneamiento físico y legal de los terrenos como parte del proceso de reubicación. Con ese compromiso de por medio, los representantes de las 52 familias compraron 
los terrenos a la comunidad y decidieron construir sus nuevas casas en Nueva Yanacona. El ex jefe del proyecto AICC me comentó que, luego de esta asamblea, un grupo de estos comuneros se dirigió al Gobierno regional para comunicar que habían conseguido un lugar donde reubicarse:

Ellos [los comuneros y comuneras de Yanacona] han buscado su terreno. La comunidad les concede un lugar en Las Lomas [Nueva Yanacona] donde ellos deben reasentarse [...] A la región [gobierno regional], ellos vienen [y] le dicen: «señor, ya tengo mi terreno ahora quiero que me lo midas. Quiero que me lo lotices». Entonces, ese papel ha hecho la región de medírselo, lotizárselo (comunicación personal, 15 de septiembre de 2015).

Para ese entonces, la relación entre las 52 familias afectadas y la comisión técnica encargada de la reubicación se encontraba en buenos términos. Los problemas inician a finales de 2013, pues el Gobierno regional quería que ellas abandonasen sus viviendas al interior del polígono sin haberlas indemnizado. Según el ex jefe del proyecto AICC, en el año 2013 no se les podía pagar por dos razones: la falta de dinero en el Gobierno regional y la suspensión del presidente regional del Cusco. La primera razón me la explicó de la siguiente manera:

Si bien es cierto que en el año 2011 teníamos bonanza económica, en el año 2013 hemos empezado a carecer de dinero y no teníamos. Como nosotros habíamos negociado con esta gente y habíamos hecho actas de compromiso en las que ellos iban a desatar sus viviendas porque necesitábamos que se libere el área del polígono, ellos tenían que haber dejado limpio el sector y nosotros haberles pagado. Ese era el compromiso [...] Pero después de haber hecho el negocio hemos empezado a tener los recortes presupuestales y no les hemos cumplido con el pago [de las viviendas]. No se le ha pagado a nadie en el ańo 2013 (comunicación personal, 15 de septiembre de 2015).

Entonces, el Gobierno regional no tenía dinero suficiente para pagarles a las familias afectadas. Al no poder cumplir con su parte del trato, ellas decidieron continuar viviendo al interior del polígono y, además, se negaron a iniciar la construcción de sus nuevas casas hasta que se les pagase. Esta situación era una acción de resistencia que retrasaba aún más el inicio del proyecto y obligaba a la comisión técnica solucionar el problema de la compensación económica.

Tuve la oportunidad de visitar Chinchero en octubre de 2013 y presenciar una reunión entre los comuneros y comuneras que vivían al interior del polígono y uno de los representantes de la comisión técnica encargada de la reubicación en lo que es ahora Nueva Yanacona. Aquel día, escuché que los comuneros reclamaban al representante del Gobierno regional el pago de sus viviendas. En respuesta, el funcionario público pidió a los presentes iniciar la construcción de las casas con 
el dinero que recibieron por los terrenos. Al final de la reunión, los comuneros y comuneras aceptaron, aunque estos manifestaron que no abandonarían el polígono del aeropuerto hasta que el Gobierno regional pague por las viviendas e instale los servicios básicos en Nueva Yanacona.

La segunda razón que retrasó el pago de la compensación y la instalación de servicios básicos fue la condena de Jorge Acurio, presidente regional del Cusco, por acusaciones de corrupción durante el tiempo que fue funcionario público en el distrito de Calca (Perú.21, 2013). Según el ex jefe del proyecto AICC, Rene Concha, el presidente del Gobierno regional que sucedió a Acurio no estaba comprometido con la construcción del aeropuerto.

[René Concha era] un presidente que desconocía de todo este proceso [de reubicación], los procedimientos de trabajo y los compromisos asumidos. Un presidente que viene con nuevos funcionarios que desconocían el proceso. Por un lado, decía él: «yo voy a luchar por el proyecto aeropuerto», pero en la práctica no lo hacía [...] Los nuevos funcionarios no han tomado en cuenta un presupuesto para el proyecto aeropuerto. Cuando se asume en 2014, no se contaba con el dinero. Es más, ni siquiera estaba en el presupuesto, se ha generado un desorden ahí. Entonces, con estas presiones de las marchas, manifestaciones y la presión del cronograma que también avanzaba se ha tenido que hacer un esfuerzo desde el ejecutivo nacional para hacer una caja y habilitar un monto para pagar el tema de las viviendas. Se empiezan a pagar las viviendas. En el mes de marzo-abril [de 2014] se pagan las viviendas y paralelamente se empieza con la demolición de las viviendas (comunicación personal, 15 de septiembre de 2015).

A mediados de 2014, el Gobierno regional recibió dinero del gobierno central con el objetivo de indemnizar a las 101 familias afectadas por sus viviendas y, además, conseguir que abandonen el polígono del aeropuerto para iniciar el saneamiento de terrenos. En este nuevo escenario, la división que existía al interior del grupo de familias afectadas se hizo evidente. Para 49 de ellas, la reubicación se reducía a una compensación económica, lo que, según el ex presidente del sector de Chaquellcocha (2013-2014), debilitó la posición de aquellos que demandaban la instalación de servicios básicos. En efecto, para las 52 familias que habían decidido mudarse a la zona de Nueva Yanacona, el proceso de reubicación implicaba, además de una indemnización, la instalación de luz, agua y desagüe. En otras palabras, no estaban dispuestas a abandonar el polígono del aeropuerto hasta que el Gobierno regional cumpliese con todos los compromisos asumidos.

No obstante, según los comuneros y comuneras con quienes conversé, los miembros de la comisión técnica encargada de la reubicación convencieron a parte de este segundo grupo y lograron que acepten el dinero. El ex presidente del sector de Chaquellcocha (2013-2014) me lo explicó de la siguiente manera: 
Nos han debilitado. A cada persona la han llamado, que ya vengan a la oficina uno por uno. Ahí es que los han hecho convencer diciendo: «Primeramente vayan avanzando. Vamos a comenzar a pagar de vuestras casas y van a tener dos o tres días de tiempo para que derrumbamos tu casa. El agua y la luz rápido lo vamos a hacer llegar». En ahí nos han mentido [...] Han tenido una estrategia para que rápido nos boten de las casas y las destruyan [...] uno por uno nos ha llevado y nos ha propuesto: "Ya, tal día te vamos a pagar de tu casa que es tanto. Tanto cuesta tu casa y ya. De lo que vas a recibir tu cheque de ahí tienes 48 horas para que puedas retirar de tu casa». Y la gente no se preguntaba de los servicios. Por la plata que han visto no se han percatado de los servicios (comunicación personal, 26 de agosto de 2015).

Al parecer, la necesidad del Gobierno regional por entregar los terrenos saneados al Ministerio de Transportes y Comunicaciones para el inicio del proyecto aeropuerto llevó a los funcionarios a realizar promesas que no estaban en condiciones de cumplir en ese momento. Para el ex jefe del proyecto AICC, las personas confiaron en las palabras de la comisión porque:

[...] creyeron en el proyecto aeropuerto y ellos dijeron: «Nosotros no estamos en contra del proyecto, somos parte del proyecto y nos retiramos y confiamos en que estos proyectos [la colocación de servicios básicos] sí nos los van a ejecutar» (comunicación personal, 15 de septiembre de 2015).

Sin embargo, esto no es lo que dicen algunos comuneros entrevistados. Hubo desconfianza de ellos y un grupo se negó a aceptar el cheque hasta que cumplieran con la instalación de servicios básicos en Nueva Yanacona. Un comunero narró de la siguiente manera su lucha por evitar ser desalojado.

Al último me han pagado. Me llamaban y no iba. Como siempre les dije: «Primero quiero ver los servicios. Ya acá estoy haciendo mi casa, por lo menos energía necesitamos». Tres personas que no queríamos movernos. Otra gente se ha prestado para que nos saquen. Nosotros queríamos que hagan llegar los servicios. Al último, mediante notificación judicial ya nos han notificado [...] Sí o sí tuvimos que retirarnos de las viviendas. Como ya se venía la campaña electoral y el cambio de gestión que se estaba por ir, nos han notificado que, en lo posterior, la plata puede remitirse al Estado. Si nosotros no quisiéramos sacarnos puede remitirse al Estado la plata (comunicación personal, 6 de agosto del 2015).

¿Qué significaba que "la plata podía remitirse al Estado»? El comunero me explicó que, de no aceptar el dinero en ese momento, ya no recibiría la compensación económica por su casa. Al parecer, según testimonio de otros comuneros, ellos no aceptaron retirarse del polígono necesariamente porque creyeron en el proyecto. En efecto, esta medida coercitiva fue crucial para que todos los pobladores aceptaran el cheque y abandonaran sus casas ante el temor de no recibir ningún tipo de 
compensación por la pérdida de sus casas. Además, otro aspecto fundamental fue que la mayor parte de comuneros afectados por el proyecto tenía otro lugar donde vivir. La movilidad de la población y su vinculación con otros lugares de residencia en el distrito fueron algunos de los otros factores indirectos que debilitaron la posición de los comuneros que exigían la instalación de servicios básicos en sus nuevas viviendas.

De esta manera, el Gobierno regional consiguió liberar el polígono del aeropuerto sin llevar a cabo un proceso de reubicación de la población que tuviese como objetivo restaurar o mejorar las condiciones de vida de las familias afectadas. Por el contrario, se enfocaron únicamente en compensarlas económicamente por las viviendas. En consecuencia, la situación de varias de ellas empeoró, pues debieron mudarse a la zona de Nueva Yanacona sin que existieran instalaciones de luz, agua y desagüe. Por lo tanto, hasta que el Gobierno regional solucionara este problema y cumpliera con su compromiso, las familias desplazadas debieron resolver por sí mismas el problema de la falta de servicios básicos.

\section{Conclusiones}

En este artículo hemos analizado los factores que facilitaron la salida de las familias afectadas y permitieron al Gobierno regional liberar el polígono del aeropuerto. Uno de estos factores, y quizás lo característico del proceso de reubicación, son las expectativas de modernidad de la población afectada con relación al proyecto. $\mathrm{Si}$ bien en Chinchero circulan comentarios y preocupaciones respecto de los impactos negativos que podría generar el constante despegue y aterrizaje de aviones, la mayor parte de la población se encuentra a favor de que este se realice, porque consideran que puede generar un mayor desarrollo económico en el distrito. Incluso la elaboración del Plan de Desarrollo Urbano hizo evidente una serie de problemáticas al interior del distrito que, a pesar de ser negativas para la población local, no llegaron a convertirse en una oposición frontal al proyecto AICC.

Además, la preponderancia de un enfoque de compensación por pérdidas para reducir el impacto de la reubicación se observa en la manera de proceder de la Comisión Técnica Regional. Bajo la premisa de reubicar únicamente las viviendas que se encontraban al interior del polígono y sin un interés por la población que residía al interior, la comisión presentó tres formas diferentes de compensación económica a través de las cuales se comprometió a otorgar una indemnización por las viviendas e instalar los servicios básicos. A este proceso, los funcionarios públicos y la población local se refieren como «reubicación». Sin embargo, este ni siquiera comparte los lineamientos mínimos establecidos por organismos internacionales como el BM, por lo que el resultado final del denominado "proceso 
de reubicación» no restableció ni mejoró las condiciones de vida de la población afectada. El Gobierno regional entregó los terrenos al Ministerio de Transportes y Comunicaciones sin cumplir con la instalación de servicios básicos acordada con las 52 familias afectadas por el proyecto del nuevo aeropuerto. En otras palabras, no hubo un proceso de reubicación de la población, sino únicamente una compensación económica por las viviendas.

Sorprende que la población haya accedido a abandonar sus viviendas sin realizar algún tipo de manifestación u oposición explícita. Como hemos señalado, una de las razones fue la presión ejercida por el Gobierno regional para que las familias afectadas recibieran el dinero. No obstante, consideramos que otro factor importante para entender la ausencia de una oposición ante el proyecto AICC han sido las expectativas de modernidad de los comuneros afectados. En otro contexto, el incumplimiento de compromisos establecidos entre las comunidades campesinas y el Estado podría haber desencadenado un conflicto social que no ocurrió en el caso de Chinchero. Sin embargo, la población local —incluyendo a las personas que debieron abandonar el polígono del aeropuerto - todavía se encuentran a favor de la construcción del proyecto de infraestructura, e incluso han circulado volantes que demandan el inicio de la obra. Además, las expectativas de modernidad y la esperanza de la población con respecto al futuro del distrito luego de iniciada la construcción del aeropuerto son uno de los elementos más importantes para comprender, por ejemplo, la gran cantidad de construcciones de material noble que para algunos está destruyendo el paisaje tradicional de Chinchero.

La falta de un plan de reubicación de la población y una oposición que reclame la instalación de servicios básicos al Gobierno regional fueron las principales razones por las que estos no fueron instalados hasta el año 2017. Durante los tres ańos que transcurrieron hasta que esto sucedió, las condiciones de vida de las aproximadamente cinco familias que vivían de manera permanente en Nueva Yanacona empeoraron por una situación que fue provocada por el accionar del Gobierno Regional del Cusco. Durante las reuniones para la elaboración del Plan de Desarrollo Urbano, incluso se mencionó que la ubicación de las viviendas de las familias afectadas representaba un riesgo para el aterrizaje y despegue de los aviones, por lo que deberían ser nuevamente reubicadas en el futuro (López Aguilar, 2017).

El caso de la comunidad de Yanacona no fue un proceso de reubicación según la forma como es entendida por el BM y los investigadores sociales que han escrito sobre el tema. En todo caso, el Gobierno Regional del Cusco denominó «reubicación» al pago compensatorio que realizó por las viviendas, pero en ningún momento actuó a través de un plan enfocado en restaurar o mejorar las condiciones de vida de las familias afectadas por el proyecto AICC. Además de las expectativas de la población por que este proyecto se realice, esto fue posible por la diversidad de 
estrategias económicas y las diferentes actividades económicas que realizaban las familias al momento del pago compensatorio que deben ser objeto de otra investigación. Además, la compensación económica que recibieron las familias afectadas a cambio de los terrenos que poseían al interior del polígono del aeropuerto les permitió construir nuevas viviendas o ampliar las antiguas casas que tenían en otros sectores de la comunidad, de manera que el proceso de liberación no fue mucho más conflictivo porque hubo familias que, según el testimonio de los comuneros con los cuales conversé, se beneficiaron con la expropiación de terrenos.

\section{REFERENCIAS}

Banco Interamericano de Desarrollo (1999). Reasentamiento involuntario en los proyectos del BID: principios y lineamientos. Washington D.C.: Banco Interamericano de Desarrollo. Recuperado de https://util.socioambiental.org/inst/esp/consulta_previa/sites/ util.socioambiental.org.inst.esp.consulta_previa/files/Consulta_reasentamento.pdf

Banco Mundial (2001). Reasentamiento involuntario. Recuperado e1 1 de junio de 2016 de http://siteresources.worldbank.org/OPSMANUAL/Resources/210384-1170795590012/OP412Spanish.pdf

Borasino, E. y Escobedo, L. (2010). Conflictos por uso de la tierra en Madre de Dios: análisis institucional y espacial en el marco de la carretera Interoceánica. En P. Ames y V. Caballero (eds.), Perú: el problema agrario en debate (pp. 573-605). Cusco: Sepia.

Castillo, J. B. (2014). Derechos de propiedad en carreteras públicas, un saneamiento pendiente. Círculo de Derecho Administrativo, 14, 175-186. Recuperado de http://revistas. pucp.edu.pe/index.php/derechoadministrativo/article/viewFile/13450/14077

Cernea, M. (1988a). Involuntary resettlement and development. Finance \& Development, 25(3), 44-46. https://doi.org/10.1596/0-8213-1036-4

Cernea, M. (1988b). Involuntary resettlement in development projects. Policy Guidelines in World Bank Financed Projects. Washington D.C.: World Bank. https://doi. org/10.1596/0-8213-1036-4

Cernea, M. (2003). For a new economics of resettlement: a sociological critique of the compensation principle. International Social Science Journal, 55(175), 37-45. https://doi. org/10.1111/1468-2451.5501004

De la Puente, L. (2013). Un país que despega, un pueblo que desaparece: La ampliación del Aeropuerto Internacional Jorge Chávez y el reasentamiento del A.H. El Ayllu. Lima: Pontificia Universidad Católica del Perú.

De la Puente, L. (2015). Un avance transformador: la ampliación del aeropuerto internacional Jorge Chávez y el reasentamiento del asentamiento humano El Ayllu, Callao. Debates en Sociologia, 41, 25-52.

Ferguson, J. (1999). Expectations of Modernity: Myths and Meanings of Urban Life on the Zambian Copperbelt. Berkeley, Los Angeles, Londres: University of California Press. 
Fort Meyer, R. (1999). El costo de transporte y la dinámica económica de las regiones. En I. Hurtado, C. Trivelli y A. Brack (eds.), Perú: el problema agrario en debate (pp. 175195). Lambayeque: Sepia.

Gobierno Regional del Cusco (2013). Directiva No 006-2013-GR.

Gobierno Regional del Cusco (2014). Resolución Ejecutiva Regional No 911-2014-GR Cuscol $P R$. Recuperado de http://www.transparencia.regioncusco.gob.pe/attach/docs_normativo/resoluciones/2014/rer.2014.0911.pdf

Harvey, P. (2010). Cementing Relations: The Materiality of Roads and Public Spaces in Provincial Peru. Social Analysis, 54(2), 28-46. https://doi.org/10.3167/sa.2010.540203

Harvey, P. y Knox, H. (2012). The Enchantments of Infrastructure. Mobilities, 7(4), 521536. https://doi.org/10.1080/17450101.2012.718935

Kanbur, R. (2003). Development economics and the compensation principle. International Social Science Journal, 55(175), 27-35. https://doi.org/10.1111/1468-2451.5501003

Lefebvre, H. (2013). La producción del espacio. Madrid: Capitan Swing.

León, C. (2015). Reubicación de pobladores por proyectos mineros en el Perú: diferencias por género y edad. En N. Henríquez, G. Damonte, M. Braig y B. Göbel (eds.), Desigualdades en un mundo globalizado (pp. 201-214). Lima: Cisepa.

López, M. (2017). El proyectodeaeropuertointernacionalyel «boom»delaconstrucción en Chinchero. Revista Argumentos, 2(11), 20-25. Recuperado de http://revistaargumentos.iep. org.pe/articulos/proyecto-aeropuerto-internacional-boom-la-construccion-chinchero/

Ministerio de Transportes y Comunicaciones (2004). Directrices para la elaboración y aplicación de planes de compensación y reasentamiento involuntario para proyectos de infraestructura de transporte. Lima: Ministerio de Transportes y Comunicaciones. Recuperado de https://www.mtc.gob.pe/transportes/socioambientales/documentos/ PACRI.pdf

Ministerio de Transportes y Comunicaciones (2005). Marco conceptual de compensación y reasentamiento involuntario. Lima: Ministerio de Transportes y Comunicaciones.

Ministerio de Vivienda Construcción y Saneamiento (2015). Plan de Desarrollo Urbano de la Ciudad de Chinchero 2016 -2025. Chinchero.

Perú.21 (2013). Condenan a presidente regional del Cusco a cuatro años de prisión suspendida. Recuperado el 27 de noviembre de 2015 de http://peru21.pe/actualidad/ condenan-presidente-regional-cusco-cuatro-anos-prision-suspendida-2161917

Rozas, P., y R. Sánchez (2004). Desarrollo de infraestructura y crecimiento económico: revisión conceptual. Santiago de Chile: Naciones Unidas.

Salas, G. (2008). Dinámica social y mineria: familias pastoras de puna y la presencia del proyecto Antamina (1997-2002). Lima: IEP.

Sumar, L. (s.f.). Anatomía de una esperanza: Nuevo Aeropuerto Internacional para el Cusco. Lima: Comuniqué Group.

Taj, M. (2017). Indígenas de Perú reubicados por la minería rechazan la nueva ciudad. Recuperado el 6 de abril de 2018 de https://ta.reuters.com/article/domesticNews/ idLTAKBN1E11KP-OUSLD 
Thorndike Elmore, A. (1983). Autopsia de un error: Proyecto Aeropuerto Internacional Chinchero, Cusco. Lima: Corpac.

Zegarra, L. (2010). Competitividad, infraestructura y desarrollo regional. In: J. Rodríguez y M. Tello (eds.), Opciones de política económica en el Perú: 2011-2015 (pp. 205-234). Lima: Fondo Editorial PUCP. 